\title{
Creating an IT Enabled New Occupation for the Disabled: A Resource Bricolage Perspective
}

\author{
Shu-Ching Wang ${ }^{*}$, Tzu-Chuan Chou ${ }^{2}$ \\ ${ }^{1}$ Graduate Institute of Management, National Taiwan University of Science and Technology, 43, Sec.4, \\ Keelung Rd., Taipei, Taiwan. \\ ${ }^{2}$ Department of Information Management, National Taiwan University of Science and Technology, 43, Sec.4, \\ Keelung Rd., Taipei, Taiwan.
}

* Corresponding author. Tel.: 886 920764367; email: sch171@gmail.com

Manuscript submitted January 30, 2018; accepted March 15, 2018.

doi: 10.17706/ijeeee.2019.9.1.46-53

\begin{abstract}
The purpose of this study is to explore how can social enterprises, when providing employment services to the disabled, escape the past framework, put people with different type and level of disabilities together as a work team to perform high-tech and high-professional, high-complexity information technology work through IT enablement. And in this process, how to make highly heterogeneous social enterprise workers, disabled workers, and non-disabled workers collaborate, gain customer acceptance with high quality product, and to create market value and achieve continued development with unique business models. Creating an innovative social model that is different from the stereotyped sheltered employment of the disabled, provides new perspectives for disabilities services organizations on service concept, the value of the disabled, the connotation of employment services, and the social perspective toward disabilities.
\end{abstract}

Key words: Disabilities, IT enablement, resource bricolage, social innovation, social enterprise.

\section{Introduction}

"Returning to society" has always been the core of Taiwanese society's thinking on the social welfare system for the disabled. It is committed to helping the disabled to integrate into the community, gaining a normal living standard, achieving a certain degree of self-reliance and autonomy, and appropriately demonstrating individual dignity and value. If people with disabilities and their households are to overcome exclusion, they must have access to work or livelihoods, breaking some of the circular links between disability and poverty [1]. However, the society's lack of understanding of the disabled, how to provide support at work and assist or make good use of their qualities in work, making it difficult for the disabled to find employment [2], [3]. Research in the United States of America has shown that $44 \%$ of workers with disabilities are in some contingent or part-time employment arrangement, compared with $22 \%$ of those without disabilities [4]. Even under the support and protection of the relevant laws and regulations such as the Law on the Protection of Entitlements and Benefits for the Disabled, it is still difficult to completely change their employment prospects. After employment, the unemployment rate is higher than that of nondisabled persons. According to the statistics of Taiwan's Ministry of Labor in 2014, the labor force participation rate of disabled people is only $19.7 \%$, which is much lower than the $58.45 \%$ of the general public; while the disabled unemployment rate is $11 \%$, which is nearly three times higher than the general 
public unemployment rate of 3.85\%, incisively showing the plight of employment of the disabled [5].

Today, the advancement of network technology and popularization of artificial intelligence pose a revolutionary impact on human life. The main purpose of this paper is explore how it is possible to make good use of the opportunities or resources brought by the development of information technology to increase the labor force participation rate of disabled people? This issue has become an important and interesting topic, however it has not yet been convincingly demonstrated. We employ the concept of organizational bricolage, which proposed by Baker and Nelson (2005), as the theoretical lens to focus on the resource-constrained context [6]. In addition, this paper draws on an in-depth case study of the experience of creating an IT enabled new occupation for the disabled from Flow Inc., the first social enterprise in Taiwan. The next section discusses the theoretical background of organizational bircolage. This discussion provides a roadmap for to analyze our case data. This is followed by a description of the case. Subsequently, the analysis and findings of the study are discussed. The final section concludes by discussing future research directions.

\section{Literature Review}

From the perspective of resource-based theory [7], the competitive advantage of an enterprise comes from the value, rarity, hard-to-imitate and hard-to-replace nature of the resources it owns. However, for many social enterprises that exist to solve social problems, the fundamental problem is the extreme lack of resources. In such circumstances, talking about competitive advantages has become somewhat distant because survival is the problem they have to face daily. Extremely limited resources may not have the generally accepted value, rarity, hard-to-imitate and hard-to-replace advantages, but are "the only" resources for disadvantaged businesses, organizations or individuals. Facing with such situation, how to help them to survive and develop has challenged the resource-based theory beyond its interpretable scope. From another perspective, in 1959, Penrose mentioned in The Theory of the Growth of the Firm [8] that even if enterprises have the same resources, they may offer completely different services or products in the market because of their different ability to utilize and integrate resources. The focus of attention has shifted from the resources owned by the enterprise to the ability to use the resources. Later, Lévi-Strauss's proposed the concept of "Bricolage" [9], that is, making use of resource at hand to make do, that is, after reorganizing the limited resources at hand, finding new problem solving solutions to create new value.

The concept points out how to create new value with constrained, existing resources, even if those resources are useless to others, as are low-value resources. Later "bricolage" is also gradually being used to study the process of entrepreneurship, and to explore how start-ups can survive or even develop in resource-constrained environments [10]-[12]. Baker and Nelson further proposed the entrepreneurial bricolage theory, pointing out that the creative utilization of existing, often neglected, forgotten resources, social resources and institutional resources at hand will bring unprecedented new value; The "making do" and reconstruction of the existing resources are effective ways to break through the constraints of resources of entrepreneurial firms, attain new business opportunities or meet the challenges [6]. Following the development of bricolage theory, our attention has shifted from focusing on optimal resources in the past to thinking about how to make the best use of existing resources, so as to find a new way out for start-ups or plights.

In summary, the bricolage theory consists of three core concepts [9]: resources at hand, combining new resources for new purposes and making do. Resources at hand refer to readily available resources, which may be material, skills or ideas. These resources are not deliberately collected for specific purposes, but are gradually accumulated unconsciously. They may seem fragmentary and useless, or very cheap or even free, but they are possible to create values beyond the expectation. Combination of resources is to find new ways 
in bricolage to combine and reuse resources, resulting in new solutions. For other purposes, some resources originally thought to be occupied or used have been re-combined and utilized, thus creating new values and solutions. This also means that such a change may be created as long as it does not rigidly adhere to the status quo and can bravely think out of the box. The process of combining resources for new purposes drives innovation and generates new "services" from existing resources. Making do means not to make excessive demand on the most perfect solution, but to achieve relatively good results with limited resources at hand. It is the pragmatic wisdom extracted from the work. Compared with constant hesitation upon whether resources are enough for taking actions, Lévi-Strauss's intentions of making do is to take active actions, using resources or opportunities available at hand to create beneficial results. However, these unplanned actions without rational planning, though seemingly rough and inadvertent, can sometimes lead to unpredictable and brilliant achievements. In the concept of making do, it also includes refusal of accepting restrictions [12]. That is, enterprises try to find out the institutional bottom line of conservative conventions. The fundamental way to create new value from bricolage of general resources is to make do by probing the accepted limits.

\section{Research Method}

Since the topic of this study is an interpretative one, the search for "How" is in line with the applicable conditions of case study [13], [14]. Therefore, case study is the main research method this article takes. Therefore, this study aims to explore how Flow Inc. can find ways as a new starter to achieve social innovation with limited resources by creatively using resource bricolage and innovative social enterprise thinking and business models. It helps employment services for physically and mentally disabled find a new way. It considers the commercial profit making on the one hand and the concept of practicing public service on the other hand. It helps enhance the sense of self-worthiness of people with disabilities while facilitate them to get stable and promising jobs and income.

We chose Flow Inc. mainly because they are the first social enterprises in Taiwan. When it was established in 2007, it was the first to propose in Taiwan that social problems should be solved and social needs should be reconciled, while commercial profiting is taken into consideration to ensure the sustainability of the programs. At that time, they identify themselves as venture capital social enterprise, with the goal of investing and incubating social enterprises. They hoped to call for more people to join social enterprises and devote themselves to public welfare by investing. However, after some hard work, they found that the non-profit organizations in Taiwan were not accustomed to thinking of business model at the time of operation. They often use fundraising as their main source of funding when implementing social solutions. Achieving sustainable solutions through commercial profiting is rarely seen. Therefore, Flow Inc. decides to transform itself into an executor, to practice the way of operating a business to solve social problems and devote themselves fully to employment service for the disabled. Starting from a layman, with limited understanding, ability and resources, they make use of the available resources and reorganize them through continuous learning, creative thinking and positive motivation, and in 2013 they put together people with disabilities to form a BIM1 Technical service team, Flow Inc. has thus become the world's first social enterprise type BIM technology services company. With continued efforts, Flow Inc. not only achieved the balance of profit and loss in cash flow within a few years, but also has become the second largest service provider in the field.

${ }^{1} \mathrm{BIM}$ is an abbreviation for Building Information Modeling, which refers to the implementation of simulation of real projects in the computer virtual space. It is a new technology, method and concept that uses the visualization of 3D models and parametric data to replace the traditional 2D CAD drawing mode, conduct professional, cross-stage collaborative work to help with the management and engineering operations for designing, construction, operation, maintenance work in construction industry. 


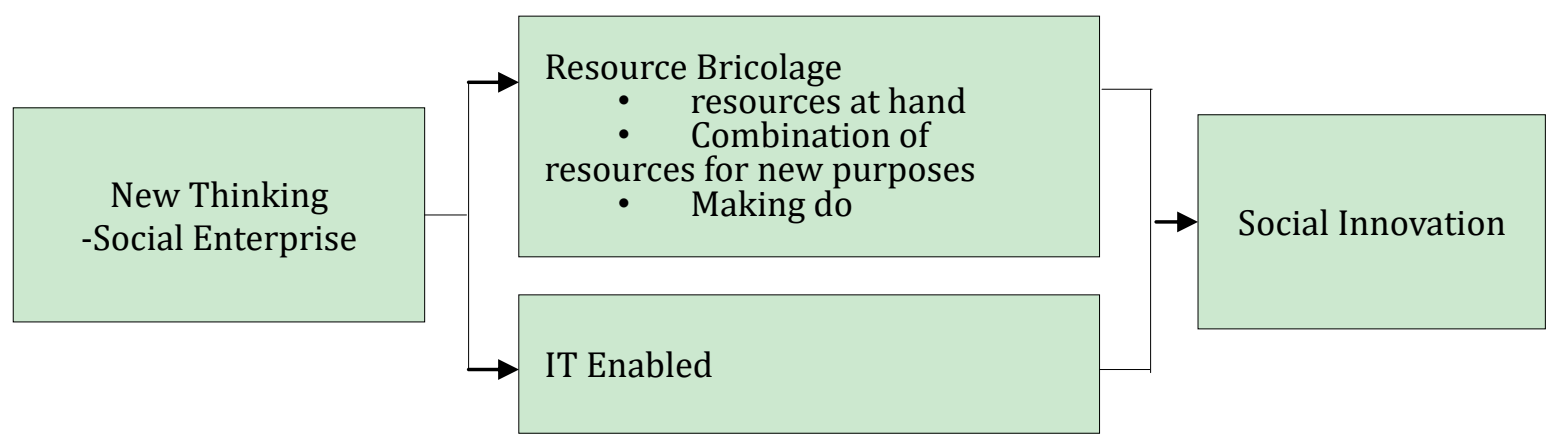

Fig. 1. Innovation process of case company.

This research mainly collects qualitative data through interviews and relevant data, media reports and literature. In the interview section, semi-structured interview was conducted through face-to-face interviews with CEOs and staff members who promote disability services programs to gain important internal information. During the interview, the interviewer's consent was acquired for recording. After the interviews, the verbatim report of the recorded content was completed. Finally, the open-coding technique of grounded theory [15] and [16] was used to identify, name, classify and describe the data found in the phenomenon.

\section{Case Description and Analysis}

Flow Inc., founded in 2007, is Taiwan's first social enterprise. Its founder, important directors and almost all employees from early days of the establishment are from the business community. Hence, it jumped out of the old fund-raising model that many social welfare agencies and non-profit organizations often adopt, to provide care and services for the underprivileged. Flow Inc. Chief Executive Director Chen point out the key point:

"Giving one the fishing rod is better than giving him fish; after that, it is also important to create a business model, active the fishing ground."

Accordingly, Flow Inc. upholds altruism and the idea of common good to devote itself into public service and to solve social problems, while taking into account commercial profit-making as a social enterprise, to help the disadvantaged to achieve sustainable problem solving and demand satisfaction. It emphasizes finding appropriate solutions for the needs of the underprivileged and social issues, and to achieve profitability and sustainability through innovative methods and business models to ensure that the underprivileged receive long-lasting solutions to their problems and meet their needs. In addition, making every effort to avoid competition and displacement of resources among the underprivileged. Therefore, when providing employment services for the disabled, special attention is needed to avoid threat to other vulnerable groups and relative deprivation, it must strive to seek different job categories, to break a new path.

The supportive employment services for the disabled provided by Flow Inc., utilized its founders and former staff's familiarity with information technology and Internet industries as advantage, developed technically complex and difficult cloud-based work - BIM works, is different from the low-cost, repetitive and low-skilled job categories traditionally provided for the disabled people. It also put people with different type and level of disability as well as those who are not physically and mentally handicapped together as a team, bring individual advantage into full play, to complete a work task. This is different from many sheltered factory or employment services' single-disability-focused strategy and work design. Apart from this, different from the general sheltered products' market positioning as help needed love products [17], Flow Inc., through different business models, advocates winning by quality products and gaining 
market recognition, even deliberately not showing the identity of their disabled workers in the early stages of sales, in order to prove their true market value. As the performance continues to grow, the disabled workers' work and economic life improved, and their sense of self-worth also enhanced. This model sets a positive example for new categories of supportive employment services for the disabled as well as for profitability, Sustainability.

Success is by no means accidental. This case study focuses on how to create value beyond the past by bricolage of different resources and advantages, adding new ideas and making unremitting efforts. On the one hand, it will further prove the resource bricolage theory, on the other hand, with the continuous development of information technologies, it is also expected to be used as a reference for creating new job types and new service modes for other employment service organizations for the disabled.

The resources at hand: From the case data analysis, the resources they have at hand include a group of staff members who have the expertise in information technology and Internet fields, but are devoted to social enterprises. These people are altruistic and willing to share good ideas and help others. They have operational experience of their business models and are full of creative thinking beyond social conventions. In addition, the resources also include those who are physically and mentally disabled who fall into different categories of disabilities and are subject to different functional limitations but have different potentialities and advantages. Even suppliers that provide BIM technical services in the market may also become the resources at hand, as they are willing to try different possibilities to cultivate professional talents as they lack of professionals though they have market opportunities. These resources may not be of value to other social enterprises or service providers for physically and mentally disabled, but the case company finally developed amazing achievements by full utilization of these resources.

Combination of resources for new purposes: The case company also trained them in car washing and refuelling work prior to introducing BIM technical services as a work project for the disabled. They also worked well with the well-known fuelling chain operations and achieved good results. However, considering that once the systematic expansion of oil refuelling and car washing work will deprive relative job opportunities from other disadvantaged people in the community. Therefore, instead of narrowing down to the existing disabled employment service category, they seek changes, get rid of the assumption of "what can a disabled person do?" and take market into consideration, seeking high value industries, reviewing every link of the industrial chain and determining whether there is any suitable space in each link for the disadvantaged whose working capabilities are in the middle of the pyramid. These links must not be overly knowledge-intensive or capital-intensive and will not deteriorate to over-low labour-intensive so as not to compete for resources with the physically and mentally challenged at the top or bottom of the pyramid. As indicted by the CEO:

"The reason why you want to see the cloud is because it is the concept of bigger pie, that is, I do not want to replace this market with the existing labour force. I am going to build an innovative market for labour forces, which is a brand-new market that will not deprive jobs opportunities from the existing labour forces."

In the end, BIM technical service was chosen as a new work area because of its high technical and irreplaceable nature, its workability of being able to form a business model that can be executed, duplicated, and at the same time achieve the sustainable goals of public welfare and profit-making. Using the expertise and acuity of past work, social enterprise staff have devoted themselves to building a new employment service model for the physically and mentally challenged and devising the business model that is rare to be seen among the relevant welfare agencies in the past. They trained more and more people with disabilities. After learning information technology from emerging fields of science and technology, they steered through the cloud to conduct collaborative cross-disciplinary and cross-stage 3D visualization and parametric data 
management to provide various management and engineering assignment assistance. The output of these training and work inputs does not aim at arousing the community's care or in exchange for the necessities of survival for today. But to focus on the value of products and market competitiveness as the key point to access to market recognition through expertise can help get rid of the myth that the employment of the disadvantaged should always be sheltered and make sustainable profit making and development possible, so that the disabled can demonstrate their values and better fit in the society to achieve the goal of balancing money making and meaning making set by social enterprises in the case study.

Making do: Work staff of the studied company who lack working experience related to case study service for vulnerable and professional training, with helping others and self-help enthusiasm, saw the employment potential of physically and mentally disabled people and their employment difficulties in reality from the observation and study of other institutions for disabled. Therefore, they selected employment services for the disabled as a focus of investment. They then use their own information technology and internet industry background, and their understanding of development trend of cloud technology, to find suitable and high value added BIM technology as an important direction of work development for physically and mentally disabled people. They also redesigned workflows by considering the specific needs of them. Different types of workers with different types of disabilities have different advantages though suffering from different limitations. Therefore, different work tasks and auxiliary equipment are given to individuals accordingly so that they can play different roles in the work team, complementing each other's advantage and creating joint value.

\section{Conclusions}

In this study, in the process of promoting BIM project for the disabled employment service, we found that Flow Inc. uses the resources at hand, follows the development trend of the cloud industry, creates a viable business model, develops work designs and processes suitable for the disabled, establishes education training system, researches, develops and uses information aids. Additionally, timely introduction of external technology or resources, i.e. exquisite operation and management through big data. As well as the introduction of EAP employee assistance programs to help people with different disabilities and non-disabled people get better job adaptation and establish effective communication and collaboration with their teams. These efforts allow each one of them to maximize their potential and improve the team's competitiveness so as to create market profits.

Through this study, via cross verification of case experience and resource bricolage theory, we learn the following:

First of all, even a seemingly resource-limited social enterprise still has some readily available resources, including knowledge, skills, ideas, or other physical resources. Each enterprise has different abilities to use these resources as long as they can think outside the box, take active actions to give existing resources different meanings and values, re-combine and use recourses to realize social innovation. Therefore, there is a great possibility to create different values.

Secondly, while the rapid advances in information technology have replaced the employment opportunities of some people with disabilities and even general people, they are grappling with the opportunities presented by this trend and re-examining the opportunities that exist in different industrial chains and making good use of them. The new tools developed by new technologies will transform resistance into a boost that will drive another wave of growth for individuals or organizations.

Thirdly, public welfare undertakings and profiting do not conflict with each other. Instead, when commercial profiting is a possible goal, beneficiaries and benefactors will have greater motivation to make greater efforts. As profiting goal approaches or reaches, their sense of self-worth will continue to increase. 
Once the commercial profits and commonweal practices coexist, the beneficiaries' sustainable future development is then foreseeable, and only then this model can be copied and spread. However, in order to achieve both, the approach of this case worth our study: In addition to full understanding of the characteristics and needs of the beneficiaries, it is also necessary to think outside of the box of "what they can do and what were the things done by the others?", and look for valuable opportunities from outside, develop profitable business models, identify projects that vulnerable groups can participate, make necessary adjustments and add supporting resources to help them better adapt and play their role, and ultimately generate valuable productivity.

In addition, in the course of case study, we also see the scope that extends further from the bricolage theory. That is, new issues and needs will emerge when resources at hand are extracted, reorganized and leveraged to make do, and then entire network is activated. As a result, the studied object's capacity of accessing resources has been improved in the process where new problems and demands emerge, and the introduction of external resources can help solve the problems accordingly.

Based on the resources-based theory of, this study confirms that limited resources will not be a stumbling block for progress. Instead, it may become a driving force for innovation; and the introduction of business thinking can achieve better results for the disadvantaged in helping others in work. It is expected to became a reference for social enterprises and other NPOs in providing employment services for people with disabilities and even more different types of social problems.

\section{References}

[1] Hoogeveen, J. G. (2005). Measuring welfare for small but vulnerable groups: Poverty and disability in Uganda. Journal of African Economies, 14, 603-631.

[2] Lillestø, B., \& Sandvin, J. T. (2014). Limits to vocational inclusion?: Disability and the social democratic conception of labour. Scandinavian Journal of Disability Research, 16(1), 45-58.

[3] World Health Organization and the World Bank. (2011). World Report on Disability. Geneva: World Health Organization.

[4] Schur, L. (2003). Barriers or opportunities? The causes of contingent and part-time work among people with disabilities. Industrial Relations, 42, 589-622.

[5] Wu, M.-C., \& S,-F, Cheng, (2012). A study on the transformation of sheltered workshop into social enterprise. Journal of Disability Research (Taiwan), 10(2), 148-162.

[6] Baker, T., \& Nelson, R. E. (2005). Creating something from nothing: Resource construction through entrepreneurial bricolage. Administrative Science Quarterly, 50(3), 329-366.

[7] Collis, D. J., \& Montgomery, C. A. (1995). Competing on resources: Strategy in the 1990s. Harvard Business Review, 73(July-August), 118-128.

[8] Penrose, E. G. (1959). The Theory of the Growth of the Firm. New York: Oxford University Press.

[9] Lévi-Strauss, C. (1967). The Savage Mind. Chicago: University of Chicago Press.

[10] Harper, D. (1987). Working Knowledge: Skill and Community in a Small Shop. Chicago: University of Chicago Press.

[11] Baker, T., Miner, A. S., \& Eesley, D. T. (2003). Improvising firms: Bricolage, account giving and improvisational competencies in the founding process. Research Policy, 32(2), 255-276.

[12] Garud, R., \& Karnøe, P. (2003). Bricolage versus breakthrough: Distributed and embedded agency in technology entrepreneurship. Research Policy, 32(2), 277-300.

[13] Chen, C. H., \& Liu, Z. (2010). The research method of case study: An overview of the classics. Journal of Management Case Studies, 3(2), 175-182.

[14] Yin, R. K. (2003). Case Study Research, Design and Methods (3rd ed.). Newbury Park: Sage Pub. 
[15] Strauss, A., \& Corbin, J. (1990). Basics of Qualitative Research: Grounded Theory Procedures and Techniques. Newbury Park, CA: SAGE.

[16] Strauss, A., \& Corbin, J. (1994). Grounded theory methodology: An overview. In N. Denzin \& Y. Lincoln (Eds.), Handbook of Qualitative Research (pp. 273-285). London: SAGE.

[17] Emerson, J., \& Twersky, F. (1996). New Social Entrepreneurs: The Success, Challenge and Lessons of Non-Profit Enterprise Creation. San Francisco: The Roberts Foundation.

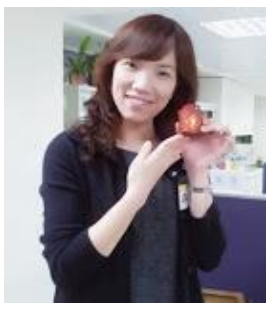

Shu-Ching Wang was born in 1974 in Taiwan. Currently she is studying at National Taiwan University of Science and Technology, Collage of Management doctoral program. In the year 2008, she completed the master degree at the Institute of Health and Welfare Policy, National Yang-Ming University, the graduation thesis was "An Establishment Model for Social Work: A preface to Yun-Shang Li's Memoir." During her University period, she was majored in Social Work at Tunghai University.

She is a qualified licensed social worker with very experienced working history. Initially, she works at the Social Department of several hospitals, later became the Director of the Department of Human Resource. She was also the supervisor of the social benefit innovation project at the Department of Social Welfare of Taipei City Government. Currently, at the same time preparing for her doctoral degree, she is appointed as the chief consultant at Shanghai KangCheng Hospital Management Consulting Co., Ltd. Providing consultations for hospital operation management. The goal of her research is to provide social innovation and to combine social resources. 